\title{
Pemutus Aliran Daya Listrik \\ Melalui Fasilitas Short Message Service (SMS) Berbasis Mikrokontroler
}

\author{
Besma Nugraha AP, Dikpride Despa, Noer Soedjarwanto \\ Jurusan Teknik Elektro Universitas Lampung \\ Jl. Prof. Sumantri Brojonegoro No. 1 Bandar Lampung 35145 \\ abez.7thstrings@gmail.com
}

\begin{abstract}
Abstrak
Perkembangan teknologi berimbas pada tingginya kebutuhan energi listrik. Oleh sebab itu, perlu dirancang sebuah alat pemutus aliran daya yang dapat memutus aliran daya dari jarak jauh dan diharapkan dengan adanya alat ini energi listrik dapat dimanfaatkan secara efisien.

Alat ini dirancang untuk dapat memutus, menghubungkan, serta mengirimkan status aktif atau tidak-aktifnya aliran daya listrik dengan beban hingga 2,2kW. Alat ini menggunakan bahasa $\mathrm{C}$ sebagai bahasa pemrograman pada mikrokontroler Atmega8 sebagai pengendali utama, TRIAC dan kontaktor sebagai sakelar dan handphone Siemens C55 sebagai penerima perintah.

Dari hasil pengujian diperoleh: (1) sistem pemutus aliran daya listrik ini dapat menerima dan menerjemahkan perintah dalam bentuk SMS, (2) sistem pemutus aliran daya listrik ini dapat memutus dan menghubung aliran daya listrik (3) sistem pemutus aliran daya listrik ini dapat mengirimkan status aktif atau tidaknya aliran daya listrik.
\end{abstract}

Kata kunci: Energi Listrik, Pemutus Aliran Daya, Mikrokontroler, SMS, Kontaktor.

\begin{abstract}
The development of advanced technology impact on the high demand for electrical energy. Therefore, need to be design a power breaker tool that can cut off the power flow remotely and expected with this appliance electrical energy can be used efficiently.

This device is designed to be breaking, connecting, and sending its status whether the flow of electrical power that is active or not-active with loads up to $2.2 \mathrm{~kW}$. The C language is can be used as programming language of ATmega8 microcontroller as the main controller, and a TRIAC as a switch and contactor Siemens C55 mobile phone as a command receiver.
\end{abstract}

From the test results obtained: (1) the breaker power flow is able to receive and translate the commands in SMS form, (2) the the breaker power flow can be disconnected and connect the electrical power flow (3) the the breaker power flow can send active or not-active status of electrical power flow.

Keywords: Electrical Power, Breaker Power Flow, Microcontroller, SMS, Contactor.

\section{Pendahuluan}

Di era modern seperti sekarang ini, energi listrik adalah salah satu energi yang sangat dibutuhkan. Seiring maju pesatnya perkembangan teknologi dan sifat konsumtif yang dimiliki masyarakat, kini hampir semua peralatan dan perabotan rumahan menggunakan energi listrik, hal ini berakibat pada kenaikan kebutuhan energi listrik tak dapat dihindari, kebutuhan manusia akan listrik pun meningkat. Namun hal tersebut tidak diikuti oleh kebijakan dan kedisiplinan konsumen energi listrik terhadap penggunaan energi itu sendiri.

Untuk mengatasi masalah ini, dan demi meningkatkan kualitas serta efisiensi penggunaan energi listrik maka diperlukan suatu alat yang dapat mengendalikan atau mengontrol 
konsumsi energi listrik dari jarak jauh dengan memutus dan menghubung aliran daya listrik melalui fasilitas Short Message Service (SMS). Pemutus aliran daya listrik yang dirancang ini diharapkan dapat menjadi solusi terhadap masalah-masalah diatas. Pemutus aliran daya listrik ini dapat mendeteksi dan menginformasikan status aktif atau tidakaktifnya nya aliran energi listrik, serta memutuskan aliran daya sesuai perintah User (pengguna) melalui layanan Short Mesage Service (SMS). Pemutus aliran daya ini dapat diterapkan pada suatu alat elektronik atau pada suatu ruangan, rumah, gedung maupun kantor.

Sebelumnya telah ada alat kontrol serupa, diantaranya ialah Anonymous, Perancangan Pengendalian Peralatan Lampu Listrik Jarak Jauh MenggunakanTelepon Seluler (http://mikrokontrolerat89s52.wordpress.com/).

Perbedaannya adalah alat kontrol yang telah ada sebelumnya bekerja pada aliran daya rendah pada satu peralatan listrik saja. Sedangkan pada sistem yang akan dirancang ini, pemutusan aliran daya pada satu bangunan dengan aliran daya tinggi dan dapat dipilih dan disesuaikan dengan kebutuhan. Aliran daya dapat dibiarkan aktif pada bagian-bagian bangunan/rumah yang memang membutuhkannya. Sehingga pemutusan aliran daya yang dilakukan dapat lebih efektif.

\section{Tinjauan Pustaka}

\subsection{Kemajuan Teknologi dan Hemat Energi}

Pesatnya kemajuan teknologi di era modern memang tak dapat dibendung. Kini, hampir semua peralatan dan perabotan rumahan telah dikonversi menjadi alat yang membutuhkan energi listrik. Aktifitas manusia yang dulunya dapat dilakukan tanpa listrik, seperti menimba air, merebus air, menanak nasi dan lain-lain, kini, hampir semua aktifitas manusia selalu bersinggungan dengan listrik. Sebut saja rice cooker, dispenser, mesin cuci, mixer/blender, televisi, lemari es, $A C$, kipas angin, pompa air, dll. Sifat masyarakat yang konsumtif, mengharapkan kepraktisan/kemudahan dalam suatu aktifitas serta harga perangkat-perangkat elektronik yang relatif terjangkau membuat keadaan semakin parah. Tak dapat dielakan, kebutuhan manusia akan energi listrik pun kian meningkat.

\subsection{Hukum-Hukum Rangkaian Listrik}

\section{a. Hukum Ohm}

Jika sebuah penghantar atau resistansi atau hantaran $(R)$ dilewati oleh sebuah arus $(I)$ maka pada kedua ujung penghantar tersebut akan muncul beda potensial $(V)$. Atau dapat dinyatakan dalam rumus :

$$
V=I \cdot R
$$

Hukum Ohm menyatakan bahwa tegangan melintasi berbagai jenis bahan pengantar adalah berbanding lurus dengan arus yang mengalir melalui bahan tersebut (E.Auer, Michael. Basics in Systems and Circuits Theory : Electric Circuits Theory Basics).

\section{b. Kirchoff's Current Law (KCL)}

Jumlah arus yang memasuki suatu percabangan atau node atau simpul sama dengan arus yang meninggalkan percabangan atau node atau simpul. Atau dapat dinyatakan dengan :

$$
\begin{gathered}
\Sigma i=0 \\
\Sigma_{\text {arus masuk }}=\Sigma_{\text {arus keluar }}
\end{gathered}
$$

Sedangkan untuk KCL Pembagi Arus (rangkaian paralel) adalah :

$$
i=\Sigma\left(\frac{V}{R}\right)
$$

Dengan kata lain jumlah aljabar semua arus yang memasuki sebuah percabangan atau node atau simpul sama dengan nol (Nahvi, Mahmood and A. Edminister, Joseph. 2003. Schaum's Outline Of Theory and Problems of Electric Circuits).

\section{c. Kirchoff's Voltage Law (KVL)}

Hukum Kirchhoff yang kedua ini menyatakan bahwa, jumlah aljabar tegangan dalam satu loop adalah nol. Atau dapat dinyatakan dengan :

$$
\Sigma V=0
$$

Sedangkan untuk KVL Pembagi Tegangan (rangkaian seri) adalah :

$$
V=\Sigma(i \cdot R)
$$

Hukum Tegangan Kirchhoff merupakan pernyataan kembali prinsip konservasi energi. 
Sebagian tegangan mungkin berupa sumber dan sebagian yang lain berupa beban. Menurut prinsip konservasi energi, energi yang diberikan oleh sumber dalam suatu selang waktu tertentu harus sama dengan energi yang diserap oleh beban selama selang waktu yang sama. (Nahvi, Mahmood and A. Edminister, Joseph. 2003. Schaum's Outline Of Theory and Problems of Electric Circuits)

\subsection{Short Message Service (SMS)}

Short Message Service (SMS) adalah layanan wireless global yang memungkinkan pengiriman pesan alphanumeric antara mobile subscriber dan eksternal system, misalnya electronic mail, paging dan voice mail system.

SMS merupakan layanan teknologi GSM yang dapat mengirim dan menerima pesan singkat berupa teks.

\subsection{Mikrokontroler}

Mikrokontroler AVR (Alf and Vegard's processor) yang digunakan adalah ATMega8 produksi Atmel Corp. Prosesor ini yang digunakan sebagai pengendali utama dari pemutus daya yang akan dibuat. Alasan penggunaan mikrokontroler ini adalah karena harga yang relatif murah, mudah diperoleh, dan kemudahan dalam pemograman, serta fitur-fitur menarik yang dimilikinya. ATmega8 memiliki 28 Pin, yang masing-masing pin nya memiliki fungsi yang berbeda-beda baik sebagai port maupun fungsi yang lainnya.

\subsection{Triode Alternating Current (TRIAC)}

Triac, sesuai namanya berfungsi sebagai saklar arus bolak-balik. Triac merupakan suatu komponen yang mempunyai susunan atas 5 lapisan bahan jenis $\mathrm{P}$ dan $\mathrm{N}$ dalam arah lain antara terminal $\mathrm{T} 1$ dan $\mathrm{T} 2$, dan dapat menghantarkan dalam dua arah. Secara elektris, Triac merupakan suatu komponen yang berkelakuan seperti dua buah SCR yang digabungkan dalam hubungan negatif terbalik. Jika triac dalam kondisi off, maka arus tidak dapat mengalir diantara terminal-terminal utamanya (saklar terbuka). Jika triac dalam $O N$, maka dengan tahanan rendah arus mengalir dari satu terminal ke terminal lainnya dengan arah aliran tergantung dari polaritas tegangan yang digunakan (saklar tertutup). Jika $\mathrm{T}_{1}$ positif maka arus mengalir dari $T_{1}$ ke $T_{2}$ dan sebaliknya jika $\mathrm{T}_{2}$ positif maka arus mengalir dari $\mathrm{T}_{2}$ ke $\mathrm{T}_{1}$. (Kustija, Jaja. 2010. Modul Mekatronika (Triac)). Pada perancangan alat pemutus aliran daya listrik ini, jenis Triac yang digunakan adalah Triac BT138, Triac ini difungsikan sebagai sakelar yang akan memutus dan menghubungkan aliran daya listrik ke beban lampu.

Berdasarkan Product datasheet, BT138-600E, NXP. 2013, rating kerja Triac BT138 adalah $600 \mathrm{~V}, 12 \mathrm{~A}, 7200 \mathrm{~W}$.

\subsection{Optoisolator MOC4031}

MOC3041 adalah perangkat optikal driver Triac terisolasi. Perangkat ini berisi GaAs (Gallium arsenide) inframerah memancarkan cahaya dioda dan diaktifkan silicon bilateral switch, yang berfungsi seperti Triac. Dirancang untuk antar muka antara kontrol elektronik dan Triac. Pada perancangan alat pemutus aliran daya listrik ini menggunakan Optoisolator MOC3041 sebagai driver Triac BT138.

\section{Metodelogi Penelitian}

Berikut adalah langkah yang dilakukan dalam penelitian ini :

\section{A. Rancangan Pemutus Daya Melalui SMS}

Pemutus aliran daya listrik ini dirancang untuk dapat memutus, menghubungkan, dan mengirimkan status ada atau tidaknya aliran daya listrik pada suatu instalasi rumah atau gedung. Pemutus daya ini memanfaatkan fasilitas Short Message Service (SMS) dan menggunakan mikrokontroler ATmega8. Pemanfaatan fasilitas SMS ini karena mengingat fasilitas SMS memiliki cakupan wilayah yang luas.

Sistem pemutus aliran daya listrik ini memanfaatkan koneksi port serial pada konektor data ponsel yang terdapat pada tiap ponsel untuk keperluan pertukaran data ponsel, sedangkan mikrokontroler berperan sebagai pengolah data serial yang diterima dari ponsel. Tipe handphone yang digunakan yaitu Siemens C55. 
Sedangkan untuk rangkaian switching atau sakelar menggunakan Triac BT138 dan kontaktor magnetik. Tiga buah Triac BT138 yang digunakan sebagai sakelar, dua diantaranya akan dibebani hanya oleh lampu dengan daya $\pm 15 \mathrm{~W}$. Sedangkan yang ke-tiga akan dihubungkan dengan kontaktor 20A dan akan dibebani dengan daya yang lebih besar, setidaknya mendekati daya kerja maksimumnya, yaitu $220-240 \mathrm{~V}, 11 \mathrm{~A}$ dan $2.4 \mathrm{~kW}$. Jadi, total ada 3 buah sakelar yang akan dikendalikan oleh mikrokontroler.

Jika ada SMS yang masuk ke handphone, maka mikrokontroler akan merekam atau menyimpan isi SMS tersebut dalam format PDU (Protocol Data Unit) di memorinya, karena handphone Siemens C55 tidak mendukung mode text dalam pengolahan datanya melainkankan mode PDU. Selanjutnya, SMS dalam forrmat PDU tersebut, kemudian dikodekan oleh pengendali mikrokontroler untuk mengidentifikasi isi SMS. Sesaat setelah SMS yang masuk telah tersimpan di memori mikrokontroler maka SMS yang tersimpan di memori handphone akan terhapus secara otomatis.

Perintah yang dapat dikenali oleh pemutus daya ini dapat dilihat pada tabel berikut :

Tabel 3.1. Kode SMS sebagai Perintah User

\begin{tabular}{|c|l|c|}
\hline Perintah & \multicolumn{1}{|c|}{ Fungsi } & $\begin{array}{c}\text { Keluaran } \\
\text { Terminal } \\
\text { Triac bt138 }\end{array}$ \\
\hline A1 & $\begin{array}{l}\text { mengaktifkan rangkaian } \\
\text { switching Triac 1 }\end{array}$ & lampu \\
\hline B1 & $\begin{array}{l}\text { mengaktifkan rangkaian } \\
\text { switching Triac 2 }\end{array}$ & lampu \\
\hline C1 & $\begin{array}{l}\text { mengaktifkan rangkaian } \\
\text { switching Triac 3 }\end{array}$ & lampu \\
\hline A0 & $\begin{array}{l}\text { menon-aktifkan rangkaian } \\
\text { switching Triac 1 }\end{array}$ & lampu \\
\hline B0 & $\begin{array}{l}\text { menon-aktifkan rangkaian } \\
\text { switching Triac 2 }\end{array}$ & $\begin{array}{l}\text { kentaktor } \\
\text { switching Triac 3 }\end{array}$ \\
\hline C0 & $\begin{array}{l}\text { untuk menanyakan status dari } \\
\text { ketiga sakelar }\end{array}$ & \\
\hline ST &
\end{tabular}

Jika SMS yang masuk tidak dikenali sebagai perintah, maka akan terabaikan, namun jika isi SMS dikenali sebagai perintah maka akan dieksekusi oleh mikrokontroler. Selanjutnya, mikrokontroler akan memerintakan handphone untuk mengirim SMS balasan dengan $A T$ Command $A T+C M G S$. Dan sistem kerja pemutus aliran daya listrik kembali ke kadaan stand-by untuk menunggu perintah selanjutnya.

Tabel 3.2. Pola SMS Balasan yang Disesuaikan dengan Perintah yang Diterima

\begin{tabular}{|c|c|}
\hline $\begin{array}{c}\text { SMS } \\
\text { Perintah }\end{array}$ & SMS Balasan \\
\hline $\mathrm{A} 1$ & $\mathrm{~A} 1 \mathrm{OK}$ \\
\hline $\mathrm{B} 1$ & $\mathrm{~B} 1 \mathrm{OK}$ \\
\hline $\mathrm{C} 1$ & $\mathrm{C} 1 \mathrm{OK}$ \\
\hline $\mathrm{A} 0$ & $\mathrm{~A} 0 \mathrm{OK}$ \\
\hline $\mathrm{B} 0$ & $\mathrm{~B} 0 \mathrm{OK}$ \\
\hline $\mathrm{C} 0$ & $\mathrm{C} 0 \mathrm{OK}$ \\
\hline
\end{tabular}

Sedangkan untuk SMS dengan perintah ST, SMS balasan yang dikirim akan menyesuaikan kondisi ketiga sakelar. Kondisi yang mungkin adalah adalah sebagai berikut :

Tabel 3.3. SMS Balasan untuk Perintah dengan Kode SMS ST

\begin{tabular}{|c|c|c|c|c|}
\hline \multirow{3}{*}{$\begin{array}{c}\text { SMS } \\
\text { Perintah }\end{array}$} & \multicolumn{3}{|c|}{ Kondisi Sakelar } & \multirow{2}{*}{ SMS Balasan } \\
\cline { 2 - 4 } & $\mathrm{A}$ & $\mathrm{B}$ & $\mathrm{C}$ & \\
\hline \multirow{4}{*}{} & ON & ON & ON & A1B1C1 \\
\cline { 2 - 5 } & ON & OFF & OFF & A1B1C0 \\
\cline { 2 - 5 } & ON & ON & OFF & A1B0C0 \\
\cline { 2 - 5 } & ON & ON & ON & A1B0C1 \\
\cline { 2 - 5 } & OFF & ON & ON & A0B1C1 \\
\cline { 2 - 5 } & OFF & ON & OFF & A0B1C0 \\
\cline { 2 - 4 } & OFF & OFF & ON & A0B0C1 \\
\cline { 2 - 5 } & OFF & OFF & OFF & A0B0C0 \\
\hline
\end{tabular}

B. Perancangan Rangkaian Elektronik 1. Rangkaian catudaya

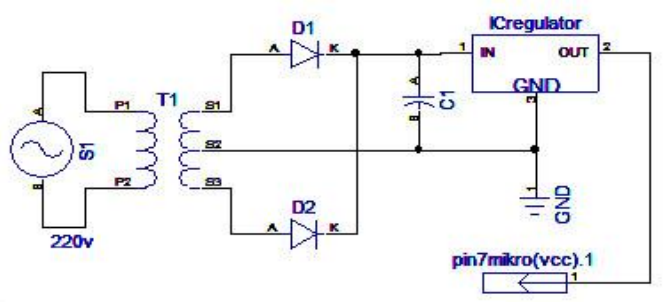

Gambar 3.1. Rangkaian catudaya 
Komponen yang digunakan pada rangkaian catu daya ini adalah :

1. Transformator, digunakan untuk mengkonversi tegangan $220 \mathrm{~V}$ AC ke rating tegangan yang diperlukan oleh sistem yaitu $5 \mathrm{~V} \mathrm{dc}$

2. Rectifier. Penyearah diperlukan untuk menyearahkan arus keluaran trafo.

3. Regulator sebagai penyetabil tegangan. Mikrokontroler hanya bekerja pada rating tegangan $3,5 \mathrm{~V}-5 \mathrm{~V}$, IC voltage regulator adalah piranti yang dapat menyetabilkan rating tegangan pada nilai tersebut.

4. Capasitor. Digunakan untuk meminimalisir sebisa mungkin tegangan ripple. Dimana besaran kapasitor yang digunakan dapat disesuaikan dengan kebutuhan atau menggunakan besaran yang direkomendasikan oleh manufaktur IC regulator yaitu sebesar $0,33 u F$.

2. Rangkaian mikrokontroler

Mikrokontroler adalah bagian utama dan merupakan "otak kendali" yang terdiri dari IC pengendali mikrokontroler ATMega8 dan untai osilator. Untai osilator terdiri dari Kristal dan dua buah kapasitor.

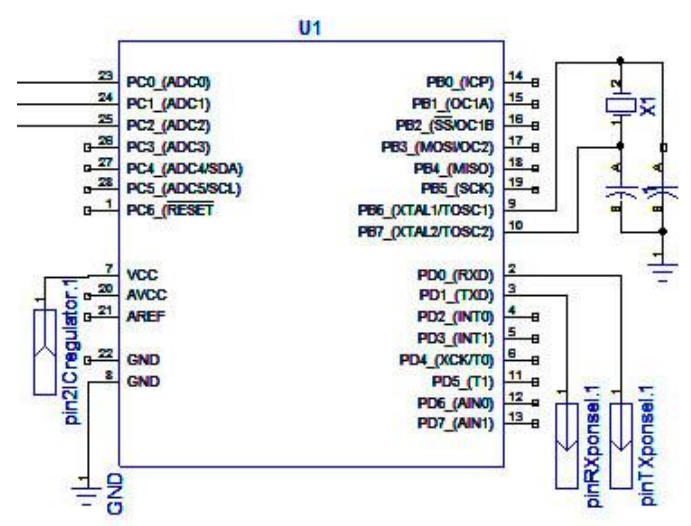

Gambar 3.2. Rangkaian mikrokontroler

Rangkaian ini juga dapat dikatakan sebagai rangkaian pegolah sinyal karena rangkaian ini mengolah data dari handphone kemudian memproses data tersebut sehingga dihasilkan output yang diinginkan. Dalam rangkaian pengolah sinyal (Minimum System ATmega8)

disusun sesuai datasheet-nya yaitu :

- osilator Kristal yang berfungsi untuk memberikan pulsa clock internal. Osilator kristal ini dihubungkan pada pin 9 (PB6) dan pada pin 10 (PB7).

- Dua buah kapasitor $22 p F$ yang berfungsi menstabilkan frekuensi. Dimana $22 p F$ tersebut adalah besaran kapasitor yang disarankan oleh manufaktur ATmega8.

3. Rangkaian komunikasi serial

Komunikasi antara handphone dengan pengaturan, data 8 bit, nonparity, dan menggunakan baud rate sebesar \pm 19200 bps, untuk pengiriman data digunakan fasilitas yang ada pada pengendali mikro yaitu fasilitas pada port D.1 (TXD) dan untuk penerimaan data dari handphone maka digunakan port D.0 (RXD) yang dihubungkan ke kabel data handphone. Selanjutnya, dikarenakan rating tegangan yang berbeda antara handphone Siemens C55 dan mikrokontroler ATmega8, dimana rating tegangan handphone adalah $3 \mathrm{~V}$ dan rating tegangan mikrokontroler adalah $5 \mathrm{~V}$, maka diperlukan diode zener interface komunikasi serial. Dengan menggunakan dioda zener ini maka tidak diperlukan IC MAX232 sebagai interface antara handphone dengan mikrokontroler.

Berikut ini adalah gambar rangkaian komunikasi serial handphone Siemens C55 dan mikrokontroler ATmega8 :

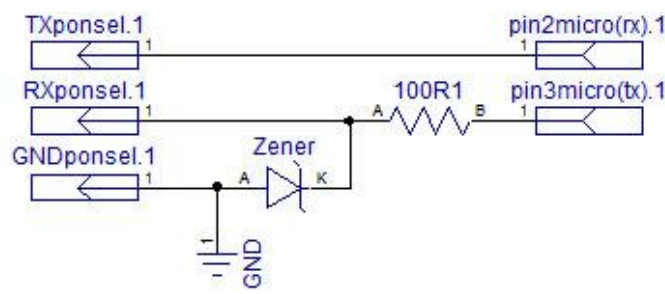

Gambar 3.3. Rangkaian Komunikasi Serial

Pada gambar diatas, rating tegangan dioda zener yang digunakan dapat 
ditentukan dengan memenuhi aturan berikut :

$$
V_{c c}>V_{z}=V_{\text {handp hone }}
$$

Dimana,

Vcc, adalah tegangan keluaran mikrokontroler yaitu $5 \mathrm{~V}$

$V_{\text {handphone, }}$ adalah rating tegangan handphone yaitu $3 \mathrm{~V}$

$V z$, adalah tegangan dioda

Maka,

$$
V z=3 \mathrm{~V}
$$

Dan besarnya nilai tahanan $R_{1}$ dapat ditentukan dengan rumus berikut :

$$
R_{1}=\frac{V_{c c}-V_{z}}{I_{z}}
$$

Dimana,

Vcc, adalah tegangan keluaran mikrokontroler yaitu $5 \mathrm{~V}$

$V z, \quad$ adalah rating tegangan dioda

$I z$, adalah arus dioda zener (menurut datasheet-nya yaitu, 20mA)

Maka,

$$
R_{1}=\frac{5-3}{0,02}=100 \mathrm{Ohm}
$$

4. Rangkaian sakelar

Input dari rangkaian ini diperoleh dari pin 23 sampai pin 25 (PC0-PC2) pada mikrokontroler, dengan hal ini mikrokontroler akan mengendalikan 3 buah Triac BT138 dengan memberikan input pada Optoisolator MOC3041. Rangkaian switching ini terdiri dari :

1. Tiga buah Triac BT138,

2. Tiga buah Optoisolator MOC3041

3. Tiga buah resistor $360 \mathrm{Ohm}$

4. Tiga buah resistor $220 \mathrm{Ohm}$

5. Dua buah lampu $\pm 15 \mathrm{~W}$

6. Satu buah kontaktor $20 \mathrm{~A}$

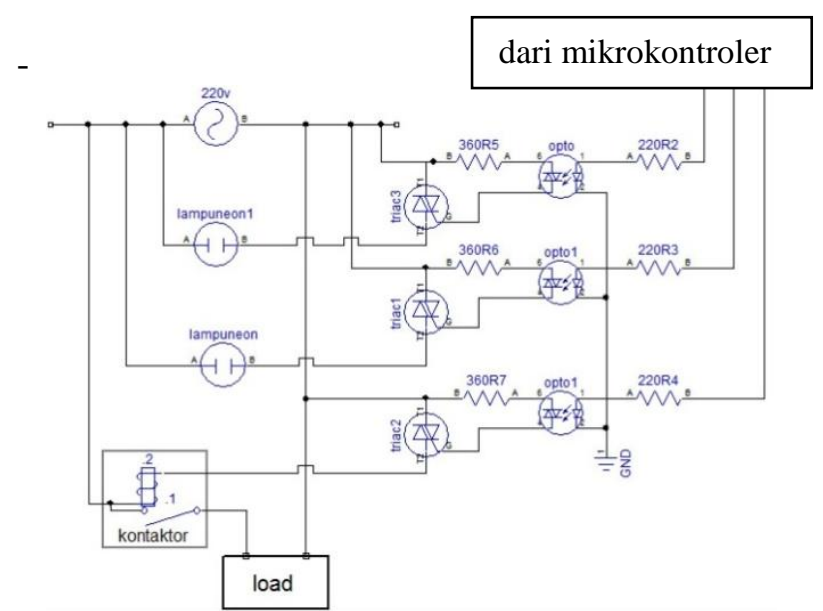

Gambar 3.4. Rangkaian Switching

Pada gambar rangkaian diatas, besarnya resistor $R_{2}, R_{3}, R_{4}$ dapat ditentukan dengan rumus :

$$
R=\frac{V c c}{I_{F}}
$$

Dimana,

$V c c$, adalah tegangan keluaran mikrokontroler

$I_{F}$ adalah arus yang diperlukan oleh Optoisolator MOC3041 (nilai $I_{F}$ sesuai datasheet adalah $15 \mathrm{~mA}$ )

Maka :

$$
\begin{aligned}
\text { Untuk } V c c 3,2 \mathrm{~V}=>R & =\frac{3,2}{0,015} \\
& =213,3 \mathrm{Ohm} \\
\text { Untuk } V c c \text { 3,3 V }=>R & =\frac{3,3}{0,015} \\
& =220 \mathrm{Ohm} \\
\text { Untuk } V c c \text { 3,4 V }=>R & =\frac{3,4}{0,015} \\
& =226,6 \mathrm{Ohm} \\
\text { Untuk } V c c \text { 3,5 V }=>R= & \frac{3,5}{0,015} \\
& =233,3 \mathrm{Ohm}
\end{aligned}
$$

Dengan demikian nilai $\mathrm{R}_{2}, \mathrm{R}_{3}, \mathrm{R}_{4}$ yang dapat digunakan adalah antara $213 \Omega$ $233,3 \Omega$. Dalam perancangan pemutus aliran daya listrik ini, nilai $R_{2}, R_{3}, R_{4}$ yang digunakan adalah $220 \Omega$.

Sedangkan besarnya $\mathrm{R}_{5}, \mathrm{R}_{6}, \mathrm{R}_{7}$ disesuaikan dengan datasheet Optoisolator MOC3041 yaitu $360 \mathrm{Ohm}$.

C. Perancangan Perangkat Lunak

Perancangan perangkat lunak pada tugas akhir ini menggunakan bahasa pemrogramana C. Perancangan perangkat 
lunak ini sangat penting, karena program yang dibuat akan menentukan program pengontrolan relay terhadap peralatan listrik yang akan dikendalikan agar bekerja dengan baik. Perancangan perangkat lunak pada mikrokontroler atmel ATmega8 terbagi menjadi 2 bagian yaitu program utama dan subrutin program. Program utama mengatur keseluruhan jalannya program yang meliputi subrutin-subrutin. Adapun diagram alir dari program utama :

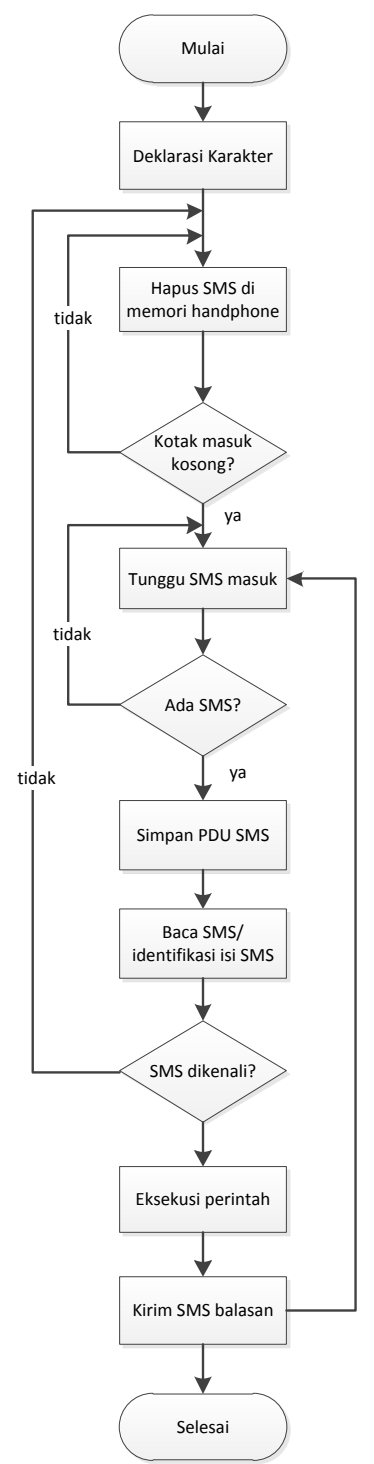

Gambar 3.5. Diagram alir program utama

\section{Hasil dan Pembahasan}

\subsection{Hasil}

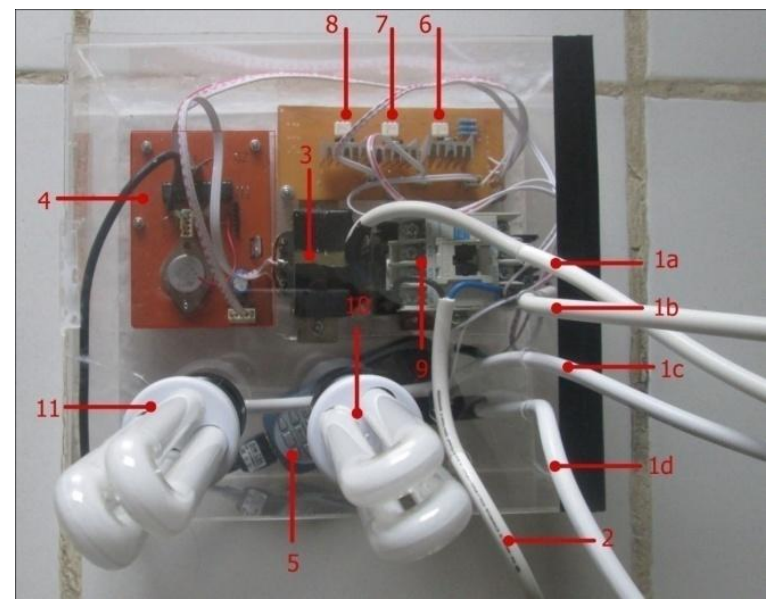

Gambar 4.1. Foto Hasil Perancangan

\subsection{Prinsip Kerja Alat}

Dalam penelitian ini dirancang sebuah prototipe alat pemutus aliran daya listrik melalui fasilitas SMS berbasis mikrokontroler.

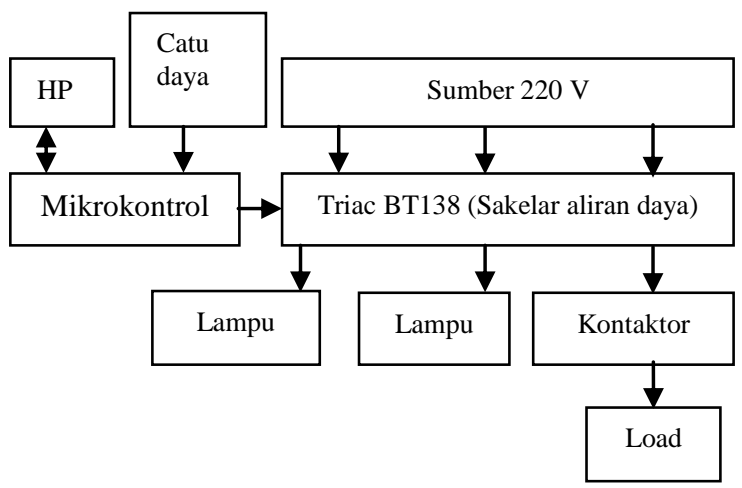

Gambar 4.2. Blok diagram rangkaian

Seperti yang ditunjukkan Gambar 4.1, dalam perancangannya alat ini dapat mengendalikan penggunaan energi listrik pada tiga titik beban.

\subsection{Pengujian Komunikasi Serial}

Pengujian komunikasi serial dilakukan menggunakan software Serial Debugger dan Hyperterminal, yaitu dengan mengirim perintahperintah AT-Command yang diawali dengan "AT+". Beberapa AT-Command yang digunakan sebagai berikut : 
- "AT"

Command ini digunakan untuk mengetahui apakah handphone bisa atau tidak diakses oleh mikrokontroler. Jika handphone membalas "OK", maka dipastikan handphone dapat berkomunikasi dengan mikrokontroler.

- "AT+CMGF

Command ini digunakan untuk mengatur mode attention atau perintah yang diberikan, yaitu "AT $+\mathrm{CMGF}=1$ " untuk mode Text dan "AT $+\mathrm{CMGF}=0$ " untuk mode PDU (protocol data unit). Namun, karena Siemens C55 tidak mendukung mode Text, maka perintah diberikan dengan mode PDU.

- "AT-CMGD"

Command ini digunakan untuk menghapus SMS.

- "AT+CNMI"

Command ini digunakan untuk mengindikasikan setiap SMS masuk, sehingga jika ada SMS masuk handphone akan memberikan umpan balik kepada mikrokontroler berupa "+CMTI = "SM",(index message)".

- "AT-CMGR"

Command ini digunakan untuk membaca isi SMS yang masuk.

- "AT-CMGS"

Command ini digunakan untuk mengirim SMS.

\subsection{Pengujian Rangkaian}

Pengujian perangkat keras merupakan cara untuk mengetahui kinerja dan kemampuan dari alat yang telah dibuat. Pengujian yang dilakukan yaitu mengukur tegangan keluaran di beberapa blok rangkaian.

Rangkaian catu daya mendapat tegangan masukan 220Vac yang kemudian diturunkan rating tegangannya menjadi $12 \mathrm{~V}$ dengan menggunakan Transformator CT-1A. Kemudian tegangan $12 \mathrm{~V}$ tersebut di searahkan menggunakan dioda penyearah. Selanjutnya untuk menghasilkan rating tegangan yang dibutuhkan rangkaian mikrokontroler yaitu sebesar 5V digunakan IC Voltage Regulator L7805V. IC Voltage Regulator ini juga berfungsi untuk menjaga ke-stabilan rating tegangan keluaran tetap pada kisaran sebesar $5 \mathrm{~V}$.

Tegangan keluaran catu daya kemudian dihubungkan ke pin 7 dan ground pada mikrokontroler sebagai input rangkaian.

Pada rangkaian komunikasi serial antara handphone Siemens C55 dan mikrokontroler terdiri dari dioda Zener $3 \mathrm{~V}$ dan resistor $100 \Omega$.

Sedangkan pada rangkaian Swithcing dengan Triac BT138 dan Simulasi Pembebanan terdiri dari :

7. Tiga buah Triac BT138,

8. Tiga buah Optoisolator MOC3041

9. Tiga buah resistor $360 \mathrm{Ohm}$

10.Tiga buah resistor $220 \mathrm{Ohm}$

11. Dua buah lampu $\pm 15 \mathrm{~W}$

12. Satu buah kontaktor 20A

Dimana input dari rangkaian ini diperoleh dari pin 23, 24, 25 mikrokontroler.

Berikut adalah hasil pengukuran tegangan pada beberapa blok rangkaian :

Tabel 4.1. Hasil Pengukuran Tegangan

\begin{tabular}{|l|l|l|}
\hline \multicolumn{1}{|c|}{ Blok Rangkaian } & \multicolumn{1}{|c|}{ Keterangan } & \multicolumn{1}{c|}{ Value } \\
\hline Catu daya & Input & $220 \mathrm{~V} \mathrm{AC}$ \\
\hline & Output & $5 \mathrm{~V} \mathrm{DC}$ \\
\hline Minimum sistem & input & $5 \mathrm{~V} \mathrm{DC}$ \\
\hline $\begin{array}{l}\text { Output pada pin } \\
23,24,25\end{array}$ & $\begin{array}{l}3,2 \mathrm{~V}-3,5 \mathrm{~V} \\
\mathrm{DC}\end{array}$ \\
\hline $\begin{array}{l}\text { Driver Triac } \\
\text { (Optoisolator) }\end{array}$ & Input & $3,5 \mathrm{~V}$ \\
\hline
\end{tabular}

\subsection{Perancangan Program Mikrokontroler}

Pengolahan data pada handphone Siemens C55 tidak mendukung mode text melainkan hanya mendukung mode PDU (Protocol Data Unit), oleh sebab itu diperlukan pengubahan dari PDU ke ASCII dan sebaliknya.

Mikrokontroler hanya akan membaca data ke-35 atau ke-37 sampai 42 dari data PDU yang masuk untuk mengidentifikasi isi pesan yang masuk pada memori handphone. Apabila data ke-35 atau ke-37 hingga 42 dikenali sebagai perintah, maka perintah tersebut akan dieksekusi.

Program utama yang berisi perintah-perintah pokok yang ditanamkan di mikrokontroler yang kemudian akan memanggil subrutin-subrutin program, yaitu: 
a. Subrutin baca dan menerjemahkan isi pesan

b. Subrutin hapus pesan pada kotak masuk

c. Subrutin eksekusi perintah

d. Subrutin balas/kirim pesan

\subsection{Pengujian Keseluruhan Sistem}

Pengujian ini dilakukan dengan mengirimkan kan perintah berupa pesan (SMS) kemudian mengamati respon alat.

Data yang diperoleh dari pengujian ini disajikan dalam tabel berikut:

Tabel 4.2 Pengujian Keseluruhan Sistem

\begin{tabular}{|c|c|c|c|c|c|}
\hline \multirow{2}{*}{$\begin{array}{c}\text { SMS } \\
\text { Dikirim }\end{array}$} & \multicolumn{3}{|c|}{ Respon Alat } & \multirow{2}{*}{$\begin{array}{c}\text { SMS } \\
\text { Diterima }\end{array}$} & \multirow[b]{2}{*}{ Ket } \\
\hline & $\begin{array}{c}\text { Relay } \\
1\end{array}$ & $\begin{array}{c}\text { Relay } \\
2\end{array}$ & $\begin{array}{c}\text { Relay } \\
3\end{array}$ & & \\
\hline ST & - & - & - & $\mathrm{A} 0 \mathrm{~B} 0 \mathrm{C} 0$ & $\checkmark$ \\
\hline $\mathrm{A} 1$ & ON & OFF & OFF & $\mathrm{A} 1 \mathrm{OK}$ & $\checkmark$ \\
\hline ST & & & & $\mathrm{A} 1 \mathrm{~B} 0 \mathrm{C} 0$ & $\checkmark$ \\
\hline $\mathrm{Cl}$ & $\mathrm{ON}$ & OFF & ON & $\mathrm{C} 1 \mathrm{OK}$ & $\checkmark$ \\
\hline ST & & & & $\mathrm{A} 1 \mathrm{BOCl}$ & $\checkmark$ \\
\hline B1 & ON & ON & ON & B1 OK & $\checkmark$ \\
\hline ST & & & & $\mathrm{A} 1 \mathrm{~B} 1 \mathrm{Cl}$ & $\checkmark$ \\
\hline $\mathrm{CO}$ & ON & $\mathrm{ON}$ & OFF & $\mathrm{COOK}$ & $\checkmark$ \\
\hline ST & & & & $\mathrm{A} 1 \mathrm{~B} 1 \mathrm{C} 0$ & $\checkmark$ \\
\hline A0 & OFF & $\mathrm{ON}$ & OFF & $\mathrm{A} 0 \mathrm{OK}$ & $\checkmark$ \\
\hline ST & & & & $\mathrm{A} 0 \mathrm{~B} 1 \mathrm{C} 0$ & $\checkmark$ \\
\hline $\mathrm{Cl}$ & OFF & $\mathrm{ON}$ & $\mathrm{ON}$ & $\mathrm{ClOK}$ & $\checkmark$ \\
\hline ST & & & & $\mathrm{A} 0 \mathrm{~B} 1 \mathrm{Cl}$ & $\checkmark$ \\
\hline B0 & OFF & OFF & ON & B0 OK & $\checkmark$ \\
\hline ST & & & & $\mathrm{A} 0 \mathrm{~B} 0 \mathrm{Cl}$ & $\checkmark$ \\
\hline $\mathrm{C} 0$ & OFF & OFF & OFF & $\mathrm{C} 0 \mathrm{OK}$ & $\checkmark$ \\
\hline
\end{tabular}

\section{KESIMPULAN DAN SARAN}

\subsection{Kesimpulan}

Dari hasil pengujian dan pembahasan dapat diambil beberapa kesimpulan, diantaranya :

1. Alat pemutus aliran daya listrik berbasis mikrokontroler dapat menerima dan menerjemahkan pesan singkat (SMS) yang dikirim oleh User sebagai perintah.

2. Alat pemutus aliran daya listrik berbasis mikrokontroler dapat mengeksekusi perintah (mengaktifkan dan menonaktifkan Switch) berdasarkan isi pesan singkat yang diterima dan mengirim pesan singkat (SMS) balasan yang berisi status Switch.

3. Mikrokontroler Atmega8, Kontaktor, Triac BT138 dan MOC3041 dapat bekerja secara efektif pada alat pemutus daya listrik berbasis mikrokontroler ini.

4. Handphone Siemens C55 dapat dikomunikasikan/diakses oleh mikrokontroler Atmega8 dan dapat digunakan sebagai penerima perintah.

\subsection{Saran}

Beberapa saran yang dapat diberikan adalah :

1. Alat pemutus aliran daya listrik rumahan ini dirancang untuk kondisi ideal, sehingga apabila listrik padam maka alat ini pun nonaktif, maka disarankan untuk menambahkan rangkaian yang dapat mem-back up catu daya apabila listrik padam.

2. Pengolahan data pada handphone Siemens C55 tidak mendukung mode text melainkan hanya mode PDU (Protocol Data Unit) saja, sehingga sangat menyulitkan saat pembuatan program. Maka disarankan untuk memilih handphone lain yang mendukung mode text pada pemrogramannya.

3. Pada rangkaian koneksi serial handphone Siemens C55 tidak dilengkapi dengan Vcc input sehingga tidak ter-charge secara otomatis melainkan harus di-charge secara manual, maka disarankan untuk menambahkan masukan Vcc, agar baterai handphone dapat ter-charge otomatis.

4. Disarankan agar User menggunakan provider GSM yang memiliki kualitas sinyal yang baik agar penyampaian pesan singkat (SMS) balasan yang dikirim oleh sistem tidak tertunda. 


\section{DAFTAR PUSTAKA}

[1] Anonymous. Perancangan Pengendalian Peralatan Lampu Listrik Jarak Jauh Menggunakan Telepon Seluler. http://mikrokontrolerat89s52.wordpress.co $\mathrm{m} /$ Diakses pada Agustus 2013.

[2] E.Auer, Michael. Basics in Systems and Circuits Theory : Electric Circuits Theory Basics. McGRAW-HILL Companies Inc, USA. 2011. Hal 13-14.

[3] http://pinouts.ru/CellularPhones-PW/siemens c55 pinout.shtml.

Siemens C55 Pin Configuration. Diakses pada Agustus 2013

[4] Kustija, Jaja. Modul Mekatronika (Triac). Bandung: Universitas Pendidikan Indonesia. 2010.

[5] Nahvi, Mahmood and A. Edminister, Joseph. Schaum's Outline Of Theory and Problems of Electric Circuits Fourth Edition. McGRAW-HILL Companies Inc, USA. 2003. Hal 24-25.

[6] Anonymous. BT138-600E Product Data Sheet. NXP Semiconductors. NXP N.V. 2013. 